\title{
Hemispatial Effects for Left- and Right-handers on a Pointing Task
}

\author{
Pamela J. Bryden ${ }^{1}$, Sara M. Scharoun ${ }^{1}$, Linda E. Rohr ${ }^{2} \&$ Eric A. Roy ${ }^{3}$ \\ ${ }^{1}$ Department of Kinesiology \& Physical Education, Wilfrid Laurier University, Waterloo, Ontario, Canada \\ ${ }^{2}$ School of Human Kinetics and Recreation, Memorial University, St. John's, Newfoundland, Canada \\ ${ }^{3}$ Kinesiology Department, University of Waterloo, Waterloo, Ontario, Canada \\ Correspondence: Pamela J. Bryden, Department of Kinesiology \& Physical Education, Wilfrid Laurier \\ University, Waterloo, Ontario, N2L 3C5, Canada. Tel: 1-519-884-0710 x4213. E-mail: pbryden@wlu.ca
}

Received: September 3, 2012

Accepted: September 25, $2012 \quad$ Online Published: November 12, 2012

doi:10.5539/ijps.v4n4p46

URL: http://dx.doi.org/10.5539/ijps.v4n4p46

\begin{abstract}
The primary goal of the current study was to determine if left-handers show an advantage for each hand in its own region of space, as do right-handers. Additionally, the study aimed to determine whether a preferred-hand advantage for movement exists in a highly-practiced task. To examine these questions, 81 right- and 60 left-handers were administered the Waterloo Handedness Questionnaire (WHQ) and completed a computer-based pointing action, where kinematic data was recorded. Here, participants were required to move to a target, located to left, midline and right of the starting position, maximizing both speed and accuracy. A 3-target location (left, midline and right space) by two hand (left, right) repeated measures ANOVA was performed for each kinematic variable, for each handedness group separately. Results indicated that left-handers showed the same spatial compatibility or object proximity effect noted by other researchers in right-handers. However, no preferred-hand advantage was found, replicating the work of Bryden and Roy (1999) who showed that the existence of the preferred-hand advantage is dependent upon the degree of spatial precision required at the movement goal.
\end{abstract}

Keywords: handedness, preferred-hand advantage, pointing task

\section{Introduction}

Differences in the processes of hemispatial effects underlying reaching movements ipsilateral and contralateral to the midline of the body have been thoroughly investigated in the literature. Research suggests movements made by the arm ipsilateral to the target demonstrates numerous advantages (including shorter reaction and movement time, and greater accuracy) in comparison to movements made by the arm contralateral to the target. Such advantages are thought to be based on intrahemispheric transmission of visual information from an ipsilateral target within the same hemisphere as the motor cortices in control of the moving limb (Carey, Hargreaves \& Goodale, 1996; Carey \& Otto-de Haart, 2001).

Biomechanical factors have also been implicated in hemispatial effects (Gordon, Gilhardi, Cooper \& Ghez, 1994; Carey et al., 1996; Carey \& Otto-de Haart, 2001; Barthélémy \& Boulinguez, 2002); demonstrating how differences in inertial forces can be used to explain kinematic differences when comparing ipsilateral and contralateral movements (Gordon et al., 1994). Additionally, hemispatial advantages have been linked to the location of the motor response direction, as opposed to the location of the target (Carey et al., 1996). More recent investigations (Carey and Otto-de Haart, 2001) have not confirmed the arguments of Carey et al. (1996) and Gordon et al. (1994), where Barthélémy and Boulinguez (2002) have suggested that biomechanical factors are unable to account for hemispatial effects on reaction time; therefore the within- versus between-hemisphere model best accounts for these differences. Overall, it may be suggested that a combination of biomechanical and hemispatial effects contribute to the advantages noted in movements toward ipsilateral targets.

Generally speaking, goal-directed movements are thought to involve the cerebral hemisphere, which controls the hand used to perform the task. Additionally, it is thought that the two hemispheres are specialized for different types of information processing (Bradshaw, Bradshaw \& Nettleton, 1990; Goodale, 1988) and that these differences ultimately lead to the observed performance differences between the hands. The body of literature on goal-directed movements has shown two types of motor asymmetries in right-handers. First, shorter reaction times for the left hand movements have been found (Haaland \& Harrington, 1989; Carson, Chua, Elliott \& Goodman, 1990; Velay \& Benoit-Dubrocard, 1999; Boulinguez, Nougier \& Velay, 2001a,b; Velay, Daffaure, 
Raphael, \& Benoit-Dubrocard, 2001), which are thought to be suggestive of a right hemispheric specialization for movement preparation and/or spatial processing. Alternately, the right hand is generally faster and more accurate than the left hand, upon the onset of movement, especially for highly practiced skills involving speed (e.g., Peters, 1996; Elliott \& Chua, 1996). The left-hemisphere system's superior ability for temporal processing of information related to perceptual and motor elements is typically used to account for the right-hand advantage, in right handers, for the performance of goal-directed movements (Flowers, 1975; Annett, Annett, Hudson, \& Turner, 1979; Bradshaw et al., 1990; Boulinguez, Velay and Nougier, 2001).

There is a wealth of research examining manual asymmetries on a range of motor tasks. Researchers have quantified the between-hand difference on tasks of strength (e.g., Provins \& Magliaro, 1993) and speed (e.g., Flowers, 1975) using such tasks as peg moving (Annett, 1967), finger tapping (Peters, 1980), dot tapping (Tapley \& M. P. Bryden, 1985) and manual aiming (Roy \& Elliott, 1986). In right-handers, it is well documented that the performance of the preferred hand is typically both faster and more accurate than the non-preferred hand (Peters, 1996; Elliott, Heath, Binsted, Ricker, Roy \& Chua, 1999; Helsen, Starkes Elliott, \& Buekers, 1998; Tremblay, Welsh, \& Elliott, 2005). In addition, researchers have examined manual asymmetries during visually-guided reaching or aiming in right-handed participants to different regions of space (e.g., Bradshaw, et al., 1990; Roy, Kalbfleisch, \& Elliott, 1994; Fisk \& Goodale, 1995; Elliott, Roy, Goodman, Carson, Chua \& Maraj, 1993; Elliott, Lyons, Chua, Goodman, \& Carson, 1995; Carey, Hargreaves, \& Goodale, 1996; Hodges, Lyons, Cockell, Reed, \& Elliott 1997). Such research typically reports that, in right-handers, each hand performs best in its own region of space, with the preferred right hand showing a movement time advantage. However, relatively few studies have examined manual asymmetries in left-handed individuals.

Peters and Servos (1989) examined left- and right-handers on a series of motor tasks, including finger-tapping, grip strength, the Purdue pegboard, a square-tracing task and a hand-writing task. They found that the between-hand differences in performance were smaller for left- than right-handed individuals. Steenhuis and Bryden (1999) also compared left- and right-handers on a series of motor tasks, and found that the non-preferred hand of left-handers performed at a significantly faster speed than the non-preferred hand of right-handers. More recently, Judge and Stirling (2003) examined unimanual performance on the Purdue pegboard and showed that the performance of the preferred hand was significantly better in right-handers but not in left-handers. However, the authors did report an advantage for left-handers on the assembly task (i.e., using both hands) of the Purdue pegboard. Stins, Kadar, and Costall (2001) examined the preference and performance abilities of left- and right-handed individuals as they reached towards objects located in different regions of working space. The authors reported no significant differences in the kinematic structure of movements (trajectory of the reach) as a function of handedness. It was found that the preferred hand was marginally faster, with less time spent in deceleration, than the non-preferred hand. This finding, however, did not appear to change as a function of the location in working space.

Perhaps more relevant to the current study, Peters and Ivanoff (1999) compared left- and right-handers on a computer mouse task, as a function of mouse experience. They found a strong right-hand advantage for reaction time in individuals who used a computer mouse on the right side, regardless of hand preference. Individuals who used a computer mouse on the left side showed no such difference between their hands. In addition, overall movement time favoured the hand with the most computer mouse experience. More recently, Boulinguez, Velay and Nougier $(2001 \mathrm{a}, \mathrm{b})$ conducted a series of experiments examining the kinematic structure of reaching movements made by both left- and right-handed individuals while pointing to targets that either had their location perturbed or not. Looking only at the unperturbed trials, a constant left-hand advantage for reaction time was found for both left-and right-handed individuals, which was interpreted as evidence of a left-hand advantage for the planning of spatial aspects the movement (Bradshaw, et al., 1990; Elliott, et al., 1993; Elliott \& Chua, 1996). In addition, a right-hand advantage was found for movement time in right-handers, but no difference was noted between the hands for left-handers.

Summarizing then, the body of research shows that ipsilateral movements prove advantageous due to the combined intrahemispheric transmission of visual information and biomechanical factors involved in hemispatial effects. As such, in right-handers, there tends to be a right-hand advantage overall in performing, however each hand performs best in its own region of space. Left-handers, in contrast, tend to have smaller performance differences between the hands than right-handers. It is not known how the two hands of left-handers perform across different regions in space.

The aim of the current study was to compare the two hands in a large sample $(\mathrm{N}=141)$ of left- and right-handed individuals on a highly practiced computer-pointing task, where they were required to move to both left and right space with both their left and right hands. We wanted to determine if left-handers show an advantage for each 
hand in its own region of space, as do right-handers (Bradshaw, et al., 1990; Roy, Kalbfleisch, \& Elliott, 1994; Fisk \& Goodale, 1995). If differences in left- and right-handers' advantages in different regions of space do exist, results could help explain, theoretically, how cerebral control for spatial processing differs in left- and right-handers. On the contrary, if left- and right-handers demonstrate the same advantages for each hand in its own region of space, results could shed light on similarities in left- and right-handers with respect to cerebral lateralization. We hypothesized that left-handers would show a similar spatial compatibility effect as right-handers.

\section{Method}

\subsection{Participants}

Eighty-one right-handers (55 females and 26 males) and 60 left-handers (38 females and 22 males) completed the Waterloo Handedness Questionnaire (WHQ) and a computer-pointing task. The WHQ was used to confirm hand preference (see Table 1 for mean hand preference scores). Each participant was a healthy, university-aged student with normal or corrected-to-normal vision. All procedures followed were reviewed and approved by the Office of Research at the University of Waterloo.

Table 1. Mean hand preference scores and standard deviations on the WHQ for male and female participants

\begin{tabular}{lll}
\hline Gender & Hand Preference & Mean (sd) \\
\hline Male (48) & Left handers (22) & $-18.05(10.16)$ \\
& Right handers (26) & $26.65(6.69)$ \\
Female (93) & Left handers (38) & $-22.68(8.89)$ \\
& Right handers (55) & $27.85(6.69)$ \\
\hline
\end{tabular}

\subsection{Apparatus}

The performance task was a computer-based pointing action. A SummaSketch graphics tablet $(30.5 \mathrm{~cm}$ by 30.5 $\mathrm{cm}$ ), interfaced with a computer, was used to sample the tablet data at a rate of $122 \mathrm{~Hz}$. All participants were seated in front of the tablet, which was placed in front of the monitor. It should be noted that a modified computer mouse was used to complete the pointing movements.

\subsection{Procedure}

Participants were required to move a mouse on the surface of a graphics tablet such that the mouse movement corresponded to the cursor movement on the monitor. Three targets, all with a radius of $10 \mathrm{~mm}$, were used in this study: one located $15 \mathrm{~cm}$ along the midline of the participant, directly in-line with the home position, a second target $15 \mathrm{~cm}$ to the left of the midline, and a third target, in the right working space, mirroring the left target. Participants were instructed to move as quickly and as accurately as possible to the center of each target when it appeared on the screen. In total, 120 trials were completed, twenty to each target, for each hand presented in a random order.

Kinematic data, including movement time, peak velocity, and time to and after peak velocity was available from the pointing task. Movement time was defined when the speed of the cursor exceeded $5 \mathrm{~mm} / \mathrm{s}$ and ended upon the mouse click, as utilized in previous studies (see Rohr, 2006). Given that participants were asked to click the mouse button at the end of their movement, this marker was deemed appropriate to quantify the end of the pointing movement (Peters \& Ivanoff, 1999; Roy, Rohr \& Weir, 2004). The velocity of the cursor at this point in time was not analyzed. Peak velocity was calculated as the maximum movement speed within the movement. Time to and time after peak velocity were calculated based on the occurrence of peak velocity.

\section{Results}

\subsection{Statistics and Data Analysis}

The data was coded with respect to right and left hands and a 3 target location (left, midline and right space) by two hand (left, right) repeated measures analysis of variance for each kinematic variable, for each handedness group separately, in order to avoid any confounding of variables. Several researchers, such as Bradshaw, et al. (1990) have reported that in right-handers, each hand performs best in its own region of space, however, it is not known whether a similar pattern prevails in left-handers. We hypothesized that left-handers would show the same spatial compatibility effect seen in right-handers. The prediction should lead to a hand by location 
interaction for each hand preference group.

In a similar study with computer mouse aiming, Peters and Ivanoff (1999) noted that hand experience is linked to performance asymmetries, as the majority of computer mouse users almost exclusively use the right-hand. As such, a right-hand reaction time superiority was noted in right-handers and left-handers with right-handed mouse experience, in comparison to left-handers with left-handed mouse experience, who demonstrated no lateral asymmetries. With practice, however, the difference between the experienced and inexperienced hand was reduced. Analysis was therefore based upon the last ten trials for each target location to minimize the impact that learning might have on performance. Statistical significance was set at $\mathrm{p}<.05$.

\subsubsection{Movement Time}

Left-handers. A significant main effect of location was found $\left(\mathrm{F}_{(2,118)}=17.08, \mathrm{p}<.01, \eta^{2}=.224\right)$, where left-handers showed shorter movement times to the midline (mean= $677 \pm 17 \mathrm{~ms}$ ) than either right space (mean= $693 \pm 18 \mathrm{~ms}$ ) or left space (mean=719 $\pm 16 \mathrm{~ms}$ ). In addition, movements to left space were significantly slower than to the midline. An interaction between hand and target location $\left(\mathrm{F}_{(2,118)}=96.89, \mathrm{p}<.01, \eta^{2}=.622\right)$ was also found. Here, Tukey's Honestly Significant Difference (HSD) post hoc analysis revealed that the left hand had significantly shorter movement times in left space than the right hand, and that the right hand had significantly shorter movement times in right space than the left hand. The hands did not differ for midline target location. Furthermore, the two hands did not differ in movement time when moving in their own region of space (i.e., left hand in left space compared to right hand in right space; see Figure 1).

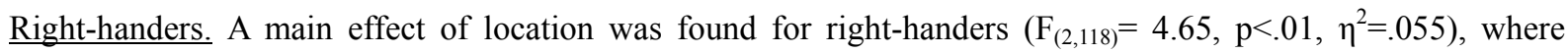
right-handers showed significantly shorter movement times to the midline (mean= $694 \pm 15 \mathrm{~ms}$ ) than either the right (mean $=709 \pm 16 \mathrm{~ms}$ ) or left space (mean= $711 \pm 15 \mathrm{~ms}$ ). Again, a hand by target location interaction $\left(\mathrm{F}_{(2,118)}=109.88, \mathrm{p}<.01, \eta^{2}=.579\right)$ was found. Here, Tukey's HSD post hoc analysis revealed that the left hand (mean= $659 \pm 17 \mathrm{~ms}$ ) was significantly faster in left space than the right hand (mean=759 $\pm 16 \mathrm{~ms}$ ), and that the right hand (mean= $675 \pm 14 \mathrm{~ms}$ ) was significantly faster in right space than the left hand. The right hand (mean= $684 \pm 15 \mathrm{~ms}$ ) was significantly faster for midline target location than the left hand (mean= $705 \pm 16 \mathrm{~ms}$ ). Additionally, as for left-handers so here for right-handers the two hands did not differ in movement time when moving in their own region of space (see Figure 1).
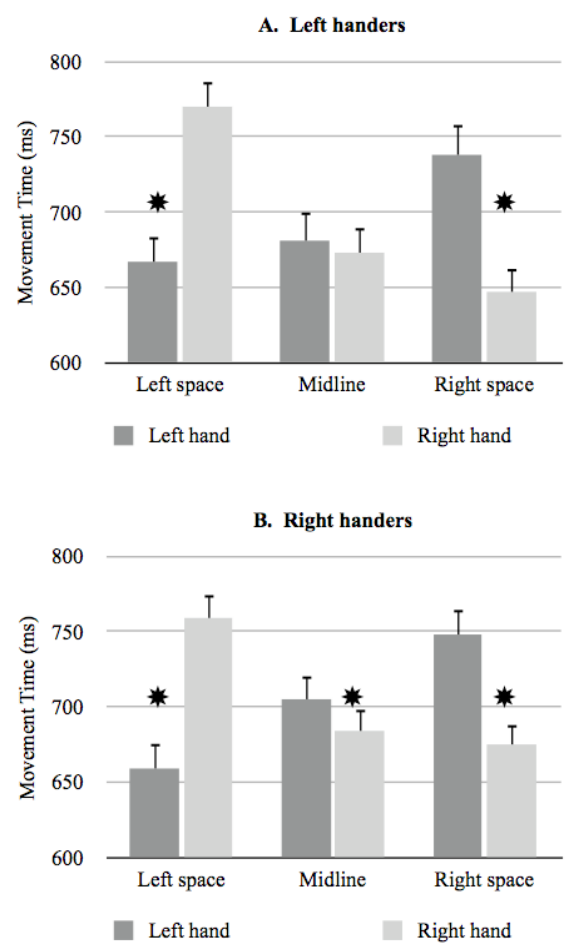

Figure 1. Movement time as a function of location in hemispace and hand Bars denote standard deviation.

Stars denote significant differences between adjacent bars $(\mathrm{p}<.05)$ 


\subsubsection{Peak Velocity}

Left-handers. A significant main effect of location $\left(\mathrm{F}_{(2,118)}=5.42, \mathrm{p}<.01, \eta^{2}=.084\right)$ was found, where peak velocity was significantly lower in left space (mean $=422.5 \pm 13.2$ ) than at either the midline (mean $=430.2 \pm$ 13.5 ) or right space (mean $=437.2 \pm 13.7)$. Again, a hand by target location interaction $\left(\mathrm{F}_{(2,118)}=155.37, \mathrm{p}<.01\right.$, $\eta^{2}=.725$ ) was found. Here, Tukey's HSD post hoc analysis revealed that the left hand had a significantly higher peak velocity in left space than the right hand, and that the right hand had a significantly higher peak velocity in right space than the left-hand. The hands did not differ for midline target location. Moreover, the two hands did not differ in peak velocity when moving in their own region of space.

Right-handers. No main effect of location was found for right-handers. However, a hand by target location interaction $\left(\mathrm{F}_{(2,118)}=114.11, \mathrm{p}<.01, \eta^{2}=.588\right)$ was found. Here, Tukey's HSD post hoc analysis revealed that the left hand had a significantly higher peak velocity in left space than the right-hand, and the right hand had a significantly higher peak velocity in right space than the left-hand. The hands did not differ for midline target location. However, unlike the left-handers the two hands did differ in peak velocity when moving in their own region of space, such that the left hand showed a higher peak velocity in left space than the right hand in right space.

\subsubsection{Time to Peak Velocity}

Left-handers. A significant main effect of location $\left(F_{(1,118)}=15.2, p<.01, \eta^{2}=.204\right)$ was found, where the midline resulted in the longest time to peak velocity (mean $=256 \pm 6 \mathrm{~ms}$ ), compared to left (mean $=238 \pm 6 \mathrm{~ms}$ ) and right space (mean $=242 \pm 6 \mathrm{~ms}$ ). The hand by target location interaction for time to peak velocity, $\left(\mathrm{F}_{(2,118)}=82.79\right.$, $\left.\mathrm{p}<.01, \eta^{2}=.584\right)$ revealed a similar trend as found with the other dependent variables. Tukey's HSD post hoc analysis revealed that the left hand spent significantly less time to peak velocity in left space than the right-hand, and that the right-hand spent significantly less time to peak velocity in right space than the left-hand. Again, no differences between the hands were found at the midline location. Furthermore, the two hands did not differ in time to peak velocity when moving in their own region of space (see Figure 2).

Right-handers. A significant main effect of location $\left(\mathrm{F}_{(1,118)}=20.73, \mathrm{p}<.01, \eta^{2}=.206\right)$ was found, where the

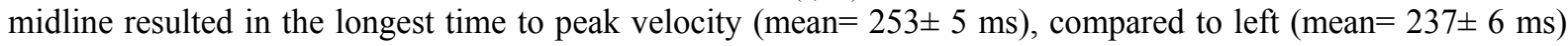
and right space (mean=236 $\pm 5 \mathrm{~ms}$ ). A two-way interaction between hand and target location was also found for time to peak velocity, $\left(\mathrm{F}_{(2,118)}=100.02, \mathrm{p}<.01, \eta^{2}=.556\right)$. Tukey's HSD post hoc analysis revealed that the left hand spent significantly less time to peak velocity in left space than the right hand, and the right hand spent significantly less time to peak velocity in right space than the left hand. Again, no differences between the hands were found at the midline location. Furthermore, the two hands did not differ in time to peak velocity when moving in their own region of space (see Figure 2).

\subsubsection{Time after Peak Velocity}

Left-handers. Again, a significant main effect of location $\left(F_{(1,118)}=35.81, p<.01, \eta^{2}=.378\right)$ was found, where the midline resulted in the shortest time after peak velocity (mean= $421 \pm 13 \mathrm{~ms}$ ), compared to left (mean= $480 \pm 12$ ms) and right space (mean $=451 \pm 13 \mathrm{~ms}$ ). More time after peak velocity was spent when moving to left space as compared to right space. A two-way interaction between hand and target location was also found for time after peak velocity, $\left(\mathrm{F}_{(2,118)}=26.64, \mathrm{p}<.01, \eta^{2}=.311\right)$. Tukey's HSD post hoc analysis revealed that the left hands pent significantly less time after peak velocity in left space than the right hand, and that the right hand spent significantly less time after peak velocity in right space than the left-hand. No differences between the hands were found at the midline location. Moreover, the two hands did not differ in time after peak velocity when moving in their own region of space (see Figure 2).

Right-handers. A significant main effect of location $\left(F_{(1,118)}=16.37, p<.01, \eta^{2}=.170\right)$ was found, where the midline resulted in the shortest time after peak velocity (mean= $441 \pm 11 \mathrm{~ms}$ ), compared to left (mean= $473 \pm 12$ $\mathrm{ms}$ ) and right space (mean= $476 \pm 11 \mathrm{~ms}$ ). A two-way interaction between hand and target location was also found for time after peak velocity, $\left(\mathrm{F}_{(2,118)}=36.06, \mathrm{p}<.01, \eta^{2}=.311\right)$. Tukey's HSD post hoc analysis revealed that the left hand spent significantly less time after peak velocity in left space than the right-hand, and that the right hand spent significantly less time after peak velocity in right space than the left hand. The right hand had a significantly shorter time after peak velocity for the midline location than the left hand. However, the two hands did differ in time after peak velocity when moving in their own region of space such that the right hand showed a longer time after peak velocity in right space than the left hand did in right space (see Figure 2). 


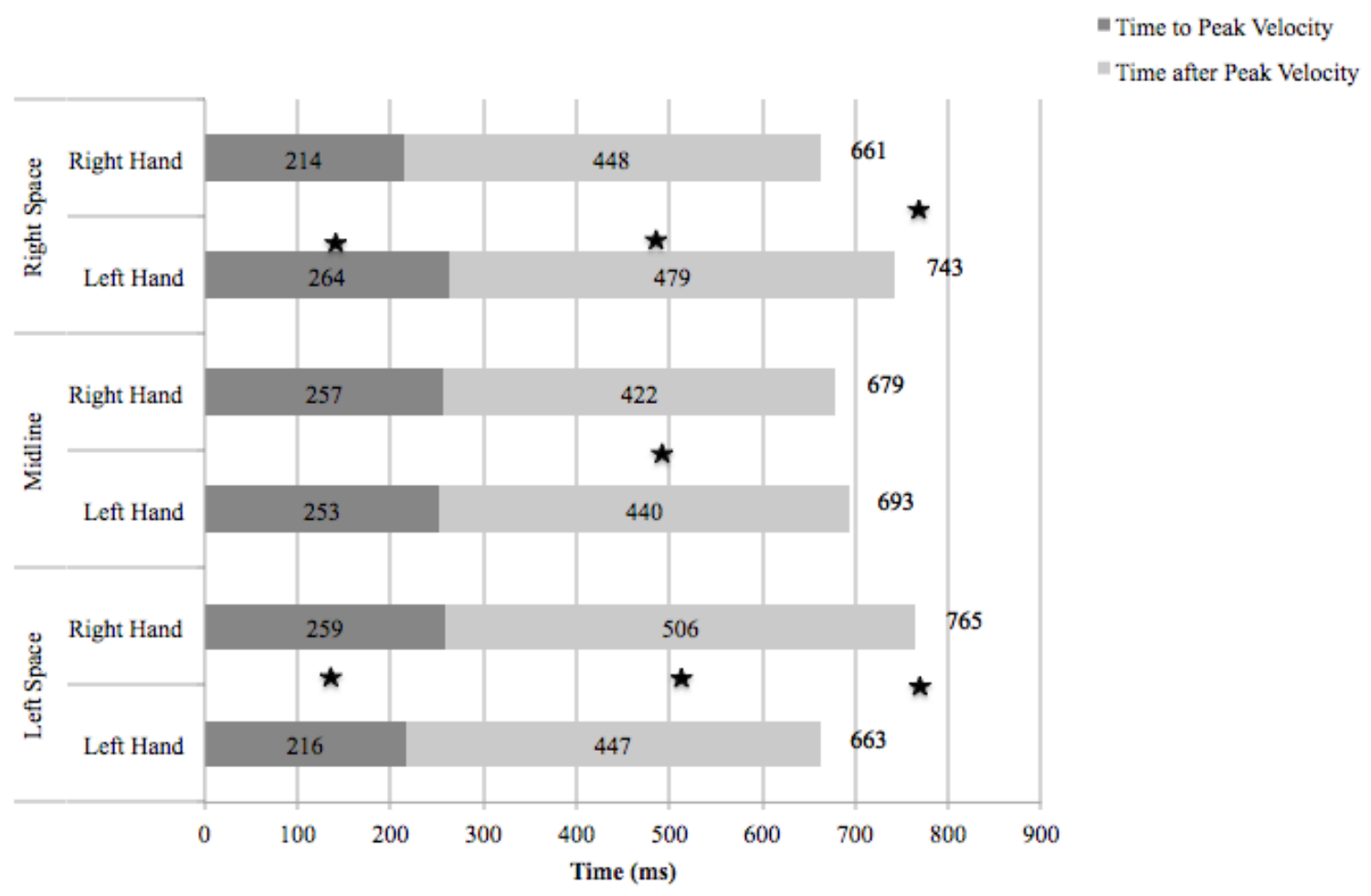

Figure 2. Time to peak velocity and time after peak velocity as a function of location in hemispace and hand Bars denote standard deviation. Stars denote significant differences between adjacent bars $(\mathrm{p}<.05)$

\section{Discussion}

The purpose of the current study was to compare the two hands in a large sample of left- and right-handed individuals on a computer-pointing task, where they were required to move to both left and right hemispace with both their left- and right-hands. The primary goal of the study was to determine if left-handers showed an advantage for each hand in its own region of space, as do right-handers (Bradshaw, et al., 1990; Roy, Kalbfleisch, \& Elliott, 1994; Fisk \& Goodale, 1995).

\subsection{Spatial Compatibility or Object Proximity Effects}

Several researchers, such as Bradshaw, et al. (1990) have reported that in right-handers, each hand performs best in its own region of space; however, it is not known whether a similar pattern prevails in left-handers. Fundamentally speaking, the effects can be explained by differences in the processes of hemispatial effects underlying reaching movements, such that arm movements ipsilateral to the target have been proven advantageous. Shorter reaction times for the left hand movements have been found (Haaland \& Harrington, 1989; Carson, Chua, Elliott \& Goodman, 1990; Velay \& Benoit-Dubrocard, 1999; Boulinguez, Nougier \& Velay, 2001a, b; Velay, Daffaure, Raphael, \& Benoit-Dubrocard, 2001; Barthélémy \& Boulinguez, 2002), which are thought to be suggestive of a right hemispheric specialization for movement preparation and/or spatial processing.

As a result, we hypothesized that left-handers would show the same spatial compatibility effect seen in right-handers. The results of the analysis confirmed this hypothesis and found that the left hand performed faster, with a higher peak velocity, less time spent reaching peak velocity, and less time spent after peak velocity, as compared to the right hand. Additionally, the right hand performed faster, with a higher peak velocity, less time spent reaching peak velocity, and less time spent after peak velocity in right space, as compared to the left hand. These findings indicate that left-handers show the same spatial compatibility or object proximity effect (Bradshaw, et al., 1990; Roy, Kalbfleisch, \& Elliott, 1994; Fisk \& Goodale, 1995) noted by other researchers in right-handers. 


\subsection{The Preferred-hand Advantage}

We had anticipated that there would be an overall preferred-hand advantage (i.e., a left-hand advantage for left-handers and a right-hand advantage for right-handers), at least in right-handed individuals, and at least for movement time, given the previous research (Boulinguez, Velay \& Nougier, 2001a, b; Stins, Kadar, \& Costall, 2001). However, interestingly, the analysis of the current study found no evidence of an advantage for the preferred-hand for either hand preference group, with respect to any of the dependent measures. The lack of a preferred-hand advantage is likely due to the relative ease of the computer-pointing task, in that the target was significantly larger than the cursor size making difficulty of the task relatively low. It is known (see Bryden \& Roy, 1999) that smaller indices of difficulty (Fitts, 1954) result in smaller, if not non-existent, performance differences between the two hands. In the current study, the index of difficulty was very small, and thus can be considered a simple task. The lack of a preferred-hand advantage thus replicates the work of Bryden and Roy (1999) that found the existence of the preferred-hand advantage to be dependent upon the degree of spatial precision required at the movement goal.

\subsection{Hand Preference}

While the analysis documented in the current paper did not directly compare left- and right-handers, some differences between the groups were noted. More specifically, left-handers showed no significant differences between the performance of the left hand in left space and the right hand in right space. Thus, the left or preferred hand of left-handers was not significantly better in left space than the right or non-preferred hand was in right space, as one might have expected. In contrast, the left or non-preferred hand of right-handers showed a higher peak velocity, and less time spent after peak velocity than the preferred right-hand, in their own regions of space. These results suggest, in right-handers, that the left hand is actually performing slightly better in left space than the right hand performs in right space. Given these findings, it is interesting to speculate why right-handers tend to cross the midline with their preferred hand when performing preferential reaching tasks (see Bryden \& Roy, 2006). This tendency is thought to occur because the preferred right hand is more proficient than the left and so is selected for use in left hemispace even though it would be biomechanically more efficient to use the left-hand. Our finding that the left hand is more proficient in left hemispace than the right hand is in right hemispace would seem to mitigate against reaching across the body with the right hand into left hemispace since the left hand is relatively speaking so much more proficient than the right hand. That said, for right-handers, the right hand was faster than the left hand at the midline; thus right-handers are more proficient with the preferred limb. Our future work will attempt to combine these performance and preferential reaching paradigms so as to better understand the relationship between manual asymmetries in performance and hand preference. In addition, we will explore whether a more difficult task would elicit an advantage for the preferred right-hand, by examining how task complexity plays a role in the spatial compatibility effect in both left- and right-handers.

\section{Conclusion}

Clearly, the current study has provided evidence, in a large sample, that both left- and right-handers show the same spatial compatibility effect. Each hand performs best in its own region of space, regardless of hand preference. In left-handers, there is no advantage for one hand in ipsilateral space, while in right-handers it is their non-preferred left hand that appears to perform better in ipsilateral space.

\section{References}

Annett, M. (1967). The binomial distribution of right, mixed, and left-handedness. Quarterly Journal of Experimental Psychology, 19, 327-333. http://dx.doi.org/10.1080/14640746708400109

Annett, J., Annett, M., Hudson, P. T. W., \& Turner, A. (1979). The control of movement in the preferred and non-preferred hands. Quarterly Journal of Experimental Psychology, 31, 641-652. http://dx.doi.org/10.1080/14640747908400755

Barthélémy, S., \& Boulinguez, P. (2002). Manual asymmetries in the directional coding of reaching: further evidence for hemispatial effects and right hemisphere dominance for movement planning. Experimental Brain Research, 147, 305-312. http://dx.doi.org/10.1007/s00221-002-1247-x

Bradshaw, J. L., Bradshaw, J. A., \& Nettleton, N. C. (1990). Abduction, adduction and hand differences in simple and serial movements. Neuopsychologia, 28, 917-931. http://dx.doi.org/10.1016/0028-3932(90)90108-Z

Bryden, P. J., \& Roy, E. A. (1999). Spatial task demands affect the extent of manual asymmetries. Laterality, 4(1), 27-37. http://dx.doi.org/10.1080/713754327 
Bryden, P. J. \& Roy, E. A. (2006). Preferential reaching across regions of working space in adults and children. Development Psychobiology, 48(2), 121-132. http://dx.doi.org/10.1002/dev.20120

Boulinguez, P., Nougier, V., \& Velay, J-L. (2001a). Manual asymmetries in reaching movement control I: Study of right-handers. Cortex, 37, 101-122. http://dx.doi.org/10.1016/S0010-9452(08)70561-6

Boulinguez, P., Nougier, V., \& Velay, J-L. (2001b). Manual asymmetries in reaching movement control I: Study of left-handers. Cortex, 37, 123-138. http://dx.doi.org/10.1016/S0010-9452(08)70562-8

Carey, D. P., Hargreaves, E. L., \& Goodale, M. A. (1996). Reaching to ipsilateral and contralateral targets: Within hemisphere visuomotor processing cannot explain hemispatial differences in motor control. Experimental Brain Research, 112, 496-504. http://dx.doi.org/10.1007/BF00227955

Carey, D. P., \& Otto-De Haart, E. G. (2001). Hemispatial differences in visually guided aiming are neither hemispatial nor visual. Neuropsychologia, 39, 885-894. http://dx.doi.org/10.1016/S0028-3932(01)00036-7

Carson, R. G., Chua, R., Elliott, D., \& Goodman, D. (1990). The contribution of vision to asymmetries in manual aiming. Neuropsychologia, 28, 12151220. http://dx.doi.org/10.1016/0028-3932(90)90056-T

Elliott, D., \& Chua, R. (1996). Manual asymmetries in goal-directed movement. In D. Elliott \& E. Roy (Eds.), Manual asymmetries in motor performance. Boca Raton : CRC Press.

Elliott, D., Heath, M., Binsted, G., Ricker, K. L., Roy, E. A., \& Chua, R. (1999). Goal-directed aiming: Correcting a force-specification error with the right and left hands. Journal of Motor Behavior, 31(4), 309-324. http://dx.doi.org/10.1080/00222899909600997

Elliott, D., Lyons, J., Chua, R., Goodman, D., \& Carson, R. G. (1995). The influence of target perturbation on manual aiming asymmetries in right handers. Cortex, 31, 685-697.

Elliott, D., Roy, E. A., Goodman, D., Carson, R. G., Chua, R., \& Maraj, B. (1993). Asymmetries in the preparation and control of manual aiming movements. Canadian Journal of Experimental Psychology, 47, 570-589. http://dx.doi.org/10.1037/h0078856

Fisk, J. D., \& Goodale, M. A. (1985). The organization of eye and limb movements during unrestricted reaching to targets in contralateral and ipsilateral visual space. Experimental Brain Research, 60(1), 159-178. http://dx.doi.org/10.1007/BF00237028

Fitts, P. M. (1954). The information capacity of the human motor system in controlling the amplitude of movement. Journal of Experimental Psychology, 47(6), 381-391. http://dx.doi.org/10.1037/h0055392

Flowers, K. (1975). Handedness and controlled movement. British Journal of Psychology, 66, 39. http://dx.doi.org/10.1111/j.2044-8295.1975.tb01438.x

Goodale, M. A. (1988). Hemispheric differences in motor control. Behavioral and Brain Research, 30, 203-214. http://dx.doi.org/10.1016/0166-4328(88)90149-0

Gordon, J., Ghilardi, M. F., Cooper, S. E., \& Ghez, C. (1994). Accuracy of planar reaching movements II. Systematic extent errors resulting from inertial anisotropy. Experimental Brain Research, 99, 112-130. http://dx.doi.org/10.1007/BF00241416

Haaland, K. J., \& Harrington, D. (1989). Hemispheric control of the initial and corrective components of aiming movements. Neuropsychologia, 27, 961-969. http://dx.doi.org/10.1016/0028-3932(89)90071-7

Helsen, W. F., Starkes, J. L., Elliott, D., \& Buekers, M. J. (1998). Manual asymmetries and saccadic eye movements in right-handers during single and reciprocal aiming movements. Cortex, 34(4), 513-529. http://dx.doi.org/10.1016/S0010-9452(08)70511-2

Hodges, N. J., Lyons, J., Cockell, D., Reed, A., \& Elliott, D. (1997). Hand, space and attentional asymmetries in goal-directed manual aiming. Cortex, 33(2), 251-269. http://dx.doi.org/10.1016/S0010-9452(08)70003-0

Judge, J. \& Stirling, J. (2003). Fine motor skill performance in left- and right-handers: Evidence of an advantage for left-handers. Laterality: Asymmetries of Body, Brain and Cognition, 8(4), 297-306. http://dx.doi.org/10.1080/13576500342000022

Peters, M. (1980). Why the preferred hand taps more quickly than the non-preferred hand: three experiments on handedness. Canadian Journal of Psychology, 34, 62-71. http://dx.doi.org/ 10.1037/h0081014

Peters, M. (1996). Hand preference and performance in left-handers . In D. Elliott \& E. Roy (Eds.), Manual asymmetries in motor performance (pp. 123142). Boca Raton : CRC Press. 
Peters, M., \& Ivanoff, J. (1999). Performance asymmetries in computer mouse control of right-handers, and left-handers with left- and right-handed mouse experience. Journal of Motor Behavior, 31(1), 86-94. http://dx.doi.org/10.1080/00222899909601894

Peters, M., \& Servos, P. (1989). Performance of subgroups of left-handers and right-handers. Canadian Journal of Psychology, 43(3), 341-358. http://dx.doi.org/10.1037/h0084226

Provins, K. A., \& Magliaro, J. (1993). The measurement of handedness by preference and performance tests. Brain and Cognition, 22, 171-181. http://dx.doi.org/ 10.1006/brcg.1993.1032

Rohr, L. (2006). Gender-specific movement strategies using a computer-pointing task. Journal of Motor Behaviour, 38(6), 431-437.

Roy, E. A. (1983). Manual performance asymmetries and motor control processes: Subject-generated changes and response parameters. Human Movement Science, 2, 271-277. http://dx.doi.org/10.1016/0167-9457(83)90022-2

Roy, E. A., \& Elliott, D. (1986). Manual asymmetries in visually directed aiming. Canadian Journal of Experimental Psychology, 40, 109-121. http://dx.doi.org/10.1037/h0080087

Roy, E. A., Kalbfleisch, L., \& Elliott, D. (1994). Kinematic analyses of manual asymmetries in visual aiming movements. Brain and cognition, 24(2), 289-295. http://dx.doi.org/10.1006/brcg.1994.1017

Roy, E. A., Rohr, L. E., \& Weir, P. L. (2004). Effect of movement termination in single- and dual-phase pointing tasks. Motor Control, 8(2), 121-138.

Steenhuis, R. E., \& Bryden, M. P. (1999). The relation between hand preference and hand performance: what you get depends on what you measure. Laterality, 4, 326. http://dx.doi.org/10.1080/713754324

Stins, J. F., Kadar, E. E., \& Costall, A. (2001). A kinematic analysis of hand selection in a reaching task. Laterality, 6(4), 347-367. http://dx.doi.org/10.1080/713754421

Tapley, S. M., \& Bryden, M. P. (1985). A group test for the assessment of performance between the hands. Neuropsychologia, 23, 215-222. http://dx.doi.org/10.1016/0028-3932(85)90105-8

Tremblay, L., Welsh, T. N., \& Elliott, D. (2005). Between-trial inhibition and facilitation in goal-directed aiming: Manual and spatial asymmetries. Experimental Brain Research, 160(1), 79-88. http://dx.doi.org/10.1007/s00221-004-1987-x

Velay, J. L. \& Benoit-Dubrocard, S. (1999). Hemispheric asymmetry and interhemispheric transfer in reaching programming. Neuropsychologia, 37(8), 895-903. http://dx.doi.org/10.1016/S0028-3932(98)00149-3

Velay, J. L., Daffaure, V., Raphael, N., \& Benoit-Dubrocard, S. (2001). Hemispheric asymmetries and interhemipheric transfer in pointing depend on the spatial components of movement. Cortex, 37, 75-90. 